\section{Science, Ethics, and Moral Status}

\author{
Harlan B. Miller \\ Virginia Tech
}

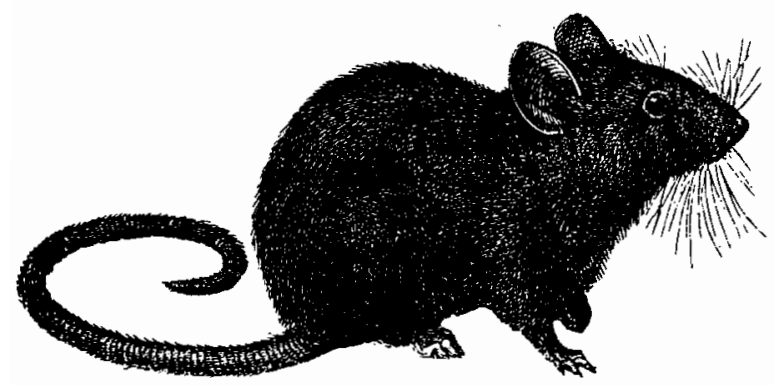

This paper has two purposes, first to discuss the nature of ethics (or moral philosophy, I take these terms to be equivalent) and second to examine the notion of moral status in general and in particular the moral status of nonhuman animals. ${ }^{1}$

The practical importance of the second purpose will be apparent to readers of this journal. But the first purpose must come first, I believe, in order to counter a number of fundamental but widespread misconceptions of ethics. It is widely believed that ethics is relative to particular cultures in a way that science is not, or that ethics is not, as science is, objective, or that ethics is somehow intrinsically emotional. These beliefs lead to the conclusion that rational and productive work on ethical questions is just not possible. If rational justification of ethical positions is taken to be impossible, one need not concern oneself with the justitication of one's treatment of animals. Those who object to accepted, customary, uses of animals are just being "emotional."

\section{I}

What is ethics? Ethics is a field of study (or the content of that field) concerned with what ought to be or with

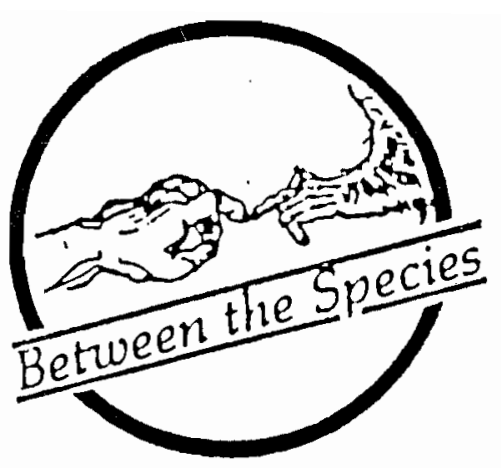

what we ought to do. We may distinguish between an ethics of action, addressed to the question "What should we do?" or "What ought to be done?" and an ethics of virtue in which the central question is "What ought we be?" or "How shall we live?" In many contexts, and on many theories, these are simply variant approaches to the same goal. We should be the sorts of people who freely choose to act in the way we ought to act. We ought to do those things we would naturally choose if we were the right sort of people. Until the last few years, much of modern moral philosophy, at least in the English-speaking world, has emphasized the ethics of action much more than the ethics of virtue. In this paper the distinction will be of little importance. ${ }^{2}$

Ethics, then, is concerned with what ought to be (what we ought to do, what we ought to be, the right and the wrong). Science, taken very generally, is concerned with what is (what the world is like, the true and the false). There is more to science than a collection of facts. Even if it were possible for us to know and to express all the truths there are, a complete listing of them would not constitute an adequate science. At a minimum, there is an additional need to subsume particular truths under general laws. And further, a proposed law of science may cover all the relevant phenomena yet still be unsatisfactory if it lacks explanatory force. It is important to stress this. The concerns of science are not limited to covering facts;

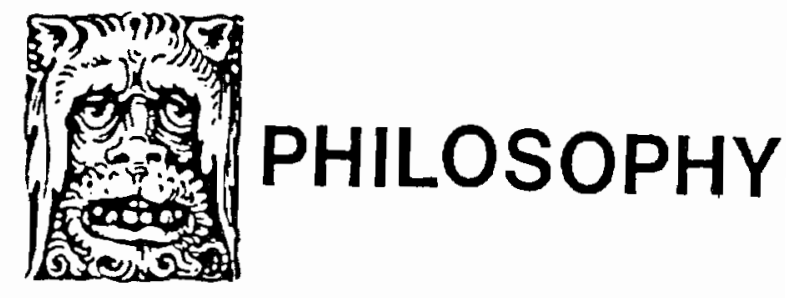


the facts are also to be explained. Inattention to this essential part of the inission of science contributes to the mistaken belief that moral philosophy (and philosophy in general) is radically unlike science.

Science and philosophy are both attempts to make sense of our world, to explain things. In the Greek origins of Western philosophy and science the two are sometimes inextricably intermixed and sometimes just indistinguishable. Although today it is quite easy to distinguish some sorts of scientific activity from some sorts of philosophical activity, it is still true that many, perhaps most, of the most interesting scientific questions either just are philosophical questions or border on and shade into philosophical questions.

In principle, the bedrock of science is observation. Scientific theory must account for the observations, save the phenomena. Observations are not simply glances, glimpses, or impressions. Not everything someone claims to have seen, observed, or just come to believe counts as an observation. Putative observations have to measure up to certain standards, which may be more or less well-defined, depending on the field. We are quite willing to throw out supposed observations as simply mistaken, biased, fraudulent, hallucinatory, or otherwise spurious.

A theory constructed to account for a set of observations may end up presenting an explanatory framework that includes most of the observations, but leaves some of them out. What happens in these situations? Suppose our theory covers $95 \%$ of the observations, but cannot account for the remaining $5 \%$. We of course simply reject the deviant $5 \%$ as due to "experimental error" of some unknown sort. In other words, even though observations are basic, we are quite willing to sacrifice observations to theoretical simplicity and/or explanatory power.

The theoretical structure of science that I have just sketched in a manner both crude and idealized is exactly parallel, I shall argue, to the theoretical structure of ethics.

Corresponding to scientific observations are our "intuitions" of right and wrong, good and bad. Just as observations are not glances or momentary impressions, so intuitions are not just transitory emotions or responses. Intuitions are our reflective evaluations, our approvals and disapprovals "in a cool hour" (to use Hume's phrase). If one's upbringing has been deficient in a certain way, one may at first react to the sight of a racially mixed couple with unreflective disapproval.
However, one may well, upon very brief reflection, reject one's own reaction and replace it by the intuition that there is nothing amiss. Why would one reject one's initial reaction? Because one is unable to justify it on the basis of moral theories or principles that one accepts as otherwise satisfactory. Moral theories are satisfactory if and to the extent that they account for most, or the most central of, our intuitions, if they possess explanatory power, and so on. At a high level of generality the criteria for the adequacy of moral theories are the same as those for the adequacy of scientific theories.

My intuitions can, over time, change as a result of my acceptance of a moral theory or some elements of a moral theory and as a result of other factors. What I perceive (intuit) as right and wrong, good and bad, is obviously influenced by my upbringing, my antecedent beliefs both moral and factual, by my culture, and by the views of friends and family. That is, my moral intuitions are significantly affected by a wide range of prior commitments and inclinations. And something very similar is true of scientific observations. It is hardly news, at this date, to be told that scientific observations are "theory-laden" and subject to bias from many sources. We see what we are looking for, we categorize our experience and perceive our environment within the limits of the conceptual frameworks we bring with us to the laboratory, to the classroom, to the market. We see what we look for, and we can see only what we are ready for. This point is at least as old as Kant and has been a commonplace in the philosophy of science since the $1950 \mathrm{~s}$. When a physicist looks at a cloud chamber, or a neuroscientist at a brain tissue section, they see more than an ignorant observer such as myself. I may see a beautiful pattern, perhaps, but no more, while the physicist sees alpha particles and the neuroscientist sees old and new cortex. Those things are really there, and my eyesight is quite adequate, but I can't see them because I don't possess the relevant theory. (Because the patterns have meaning for the scientists it may be more difficult for them to appreciate the sort of beauty I may see in the images.) Our commitunents, our inclinations, our theories influence our scientific observations and our moral intuitions alike.

It may not be amiss at this point, since I have just mentioned the influence on one's ethical intuitions of one's cultural background, to turn to the claim that different cultures have different ethics. It is of course 
true that different cultures may well instill in their members different beliefs about right and wrong. But it certainly does not follow that all these beliefs are equally correct. Different cultures may instill in their members different scientific beliefs. If Cora Du Bois is correct, the Alorese in the late 1930s believed that numerous acts of intercourse were necessary for the formation of a human fetus and, thus, that a single act of intercourse could not suffice for the birth of a child. ${ }^{3}$ The Alorese were just mistaken. The cultural transmission of a belief is no evidence for its correctness. Some at least of my ancestors believed that human slavery (of "inferior races") was morally acceptable, and this belief was culturally transmitted. They were wrong. A society can embody and transmit false ethical beliefs just as it can embody and transmit false scientific beliefs. My ancestors' slavery-justifying beliefs were no more true than were the Alorese reproductive beliefs.

People sometimes use a curious locution of the form "true for X," where $\mathrm{X}$ is some person or group, and would say that the belief that slavery is justified was true for my great-grandfather. But to say that some belief of mine is true for me is either just to say that I believe it or is evidence of some deep muddle about the relation between truth and belief. To suggest that slavery was morally justified for my ancestors, because they believed it was, is exactly as sensible as suggesting that Alorese reproductive physiology was different from that of contemporary Italians, because Alorese and Italian beliefs differed. Cultures can just be mistaken, as can individuals. And mistakes, by cultures or individuals, need not be criminal and may in some cases be almost inescapable.

(That two cultures have conflicting moral rules need not mean that either is incorrect. There are some matters about which it is important to have a rule, but exactly which rule is chosen is morally indifferent. Such cases are common in the law. It is essential to specify which side of the road traftic will keep to, but either side will do.)

There is scientific progress, and there is moral progress. The human race is, in general, more free of unjustified discrimination than it was 50 years ago. Freedom of speech is more widely recognized, at least on paper. The rights of individuals to deviate from the norm, to be left alone, and to have their special needs met, are more widely granted. We are, as a species, less racist and less sexist than we used to be. Slavery is tolerated almost nowhere. This is moral progress. Moral progress is not as striking and perhaps not as widespread as scientific and technological progress, but it has been made.

It has been claimed that scientific disputes are decidable in ways that ethical disputes are not. Of course some low level scientific questions can be answered in satisfyingly clear-cut ways. The question of whether a particular Tursiops brain weighs 1600 or 1700 grams may be quite easy to answer. The question of the mean brain weight for adults of that species can also be answered, if not so easily. But consider the following pair of questions. Is the weight of porpoise brains of any significance for our judgments of porpoise intelligence? Is porpoise intelligence of any significance for our judgments of the moral status of porpoises? It is not at all apparent how we should even begin to search for answers to these questions. But it is not obvious that an answer to the morai member of this pair need be any more elusive than an answer to the scientific member.

Many of the most interesting and important questions cannot be resolved by measurement. Take the opposition between evolutionary theory and so-called creationism. I am convinced of the reality of evolution, but I can point to no particular facts, and certainly to no measurements, that show creationism to be false. Creationism is a very poor theory despite the fact that it, in at least a minimal sense, accounts for all our observations and measurements. Creationism fails to cohere with the rest of our scientific picture of the world, and it fails to provide genuine, non-question-begging explanations. To say that animals and plants are the way they are because God has made them that way has no explanatory power, for no matter how plants and animals were, such an "explanation" would account for it. An explanation that can be guaranteed to explain any conceivable phenomenon really explains nothing.

When faced with two competing theories, one argues that one is better than the other because it accounts for antecedent intuitions and observations of various sorts, because it coheres with other theories, because it is powerful in generating explanations, and so on. This is the way scientists argue every day. Such arguments are analogous to, and sometimes are, philosophical arguments. Philosophers argue for their theories in just these ways, that the theories account for our experience and for our antecedent beliefs, that they provide satisfying explanations of the phenomena. 
Both scientific and philosophical theories sometimes have unintuitive implications. But if a theory is otherwise sufficiently strong, it may force one to reject or revise the "intuitions," be they noral or scientific, with which it conflicts.

Progress in both science and ethics is a matter of developing theories of increasing inclusiveness and coherence, theories that make sense of our intuitions and discipline them. We are an inquisitive species, and we want general explanatory theories both of what the world is like and of what is right and wrong. We want a general account of goodness just as we want a general account of color; that's the kind of animal we are.

Suppose someone were to object to my assimilation of ethics to science by insisting on a fundamental difference in subject matter. Such an objector claims that the increasing coherence and inclusiveness of scientific theories is an indication of increasing adequacy because there really are scientific facts. There is a world out there that we encounter at least occasionally and partially, and our increasing success in these encounters indicates that our picture of the world is improving. But, says this objector, the increasing colnerence and inclusiveness (if such there is) of ethical theory is no guarantee that such theory is any more than well-constructed myth, for there is no external moral world against which the theory is tested.

This objection may be answered in two ways. First, one may say that our moral intuitions give us the same evidence of an independent moral reality that our observations give us of scientific reality. Or, second (and these replies are not incompatible), it may be pointed out that on some theories of science (e.g. those of Peirce and his successors) scientific truth is that to which, in the ideal we hope to approach, all researchers agree. Ethical truth can be, and has been, defined in the same way. What is right is what all fully informed, disinterested, rational observers agree to be right.

But our objector may persist. "No," he or she may say, "there really is an objective physical world, as may be seen from the fact that people with false scientific beliefs fail to deal satisfactorily with their enviroments, and those with generally correct scientific beliefs minimize aversive experiences. In contrast, people with opposed ethical views get along equally well, from which it may be inferred that there is no realm of objective moral facts." This is a plausible objection, but it may be rebutted from two different directions. First, better ethical views may well have "survival value," especially if the unit considered is a culture which espouses and inculcates the views. Contrary both to some folk wisdon and some pop sociobiology, nice guys and nice societies don't always finish last. Since they are unlikely to destroy themselves, they inay well finish first. Second, it is clear that one may accept false scientific theories and still fare quite well. Millions of people believe fervently in contemporary astrology, surely one of the most ludicrous theories imaginable, without discernible decrease in life expectancy. Devoutly believing in Lysenkoist biology had great survival value in the Soviet Union for several decades. These are striking cases but not exceptions. Most humans can, and many do, live reasonably happy and successful lives while believing vast numbers of scientific and metaphysical (and ethical) falsehoods. Curiosity, as I noted earlier, is characteristic of our species, and some of us have emphasized and formalized and disciplined this characteristic by becoming scholars. It is probably salutary, if depressing, to remind ourselves that hundreds of millions (billions) of our conspecifics manage to build and repair automobiles, win friends and gain power, avoid walking into walls, and have and raise children without knowing or caring about the questions, and standards for answers, that we hold dear. One can tolerate, in other words, a large amount of bad theory, both in ethics and in science, without significant impact on one's chances of survival. In order to survive we need only do the right thing most of the time. We need not do it for the right reason, or understand why it is the right thing. Correct (morally or scientifically) action may well generally lave survival value, but correct explanation probably does not.

I have not been arguing that ethics is exactly like the sciences. That would be impossible, since the sciences are surely not exactly like one another. My claim is that ethics is, like physics and history and psychology and economics, an organized and rational inquiry into an aspect of the world we experience. It shares with other inquiries a structure in which theories are constructed to account for data and data is screened and sorted in the light of theory. There is considerable deep disagreement in ethical theory at present, and there are issues about which contending parties care deeply. The same can be said of other fields, past and present. There is no fundamental gap between science and ethics.

Let that be enough talk about moral philosophy for now. It is time to do some. 
II

Any moral theory must include or presuppose some theory of moral status. An entity may be a moral agent or a moral patient or both or neither. A moral agent is something capable of action, the acts of which may properly be evaluated as right or wrong. My actions may correctly be so evaluated, but not those of a very young child. The very young, the insane, the severely retarded, and the comatose are not moral agents. Normal human adults are and so, perhaps, are adult animals of some other species, and perhaps corporations and nations.

A moral patient, on the other hand, is an entity the treatment of which may properly be evaluated as right or wrong. A human infant is not a moral agent but is a moral patient, for it does matter how an infant is treated. It is wrong to cause unnecessary pain to an infant, and wrong intrinsically. It may also be wrong to destroy my favorite pencil, but only derivatively, only because it makes me unhappy. The pencil is not a moral patient. Humans are, in general, moral patients and so are many other sorts of animals. It is wrong, intrinsically wrong, to cause gratuitous pain to a dog or a mouse or a porpoise or a seagull.

Since we adult humans are typically both moral agents and moral patients, it is easy to overlook the distinction between agency and patiency in the moral realm. This can lead to serious confusion. I once heard a paper entitled "Ethics is to Govern Human Beings Only." This sentence is importantly ambiguous, for it may be taken to mean that only human beings can be moral agents (only they are morally responsible, only they can be governed by moral rules) or that only human beings can be moral patients (only what is done to humans is of moral concern). Both of these interpretations, I believe, yield false sentences, but the first is at least faintly plausible while the second is not. It is easy, if one is not clear on the agent/patient distinction, to transfer to the second reading some of the plausibility of the first.

That other animals as well as humans are moral patients does not entail that they are entitled to equal moral concern. Not all moral patients are equal. This is widely but usually obscurely recognized. As a rational reconstruction of what I take to be common features of the views of most people today, I suggest the following "theory" of moral patients. Moral patients fall into three groups. Group A consists of persons in the moral sense of the word. It is generally taken that all and only humans are persons, but this is surely false. Persons are both moral agents and moral patients. They are possible contractors. Other moral agents, if there are any, such as corporations or states, are either denied to be moral patients at all or are placed in Group C.

Group B consists of all other sentient beings. These entities can suffer, and suffering matters. They are, however, incapable of rational actions and, thus, cannot be moral agents. All sentient nonhuman animals are placed in this category. Group $\mathrm{C}$ consists of a heterogeneous collection the members of which have in common that they are not sentient and that they are thought by some persons (at least a few sane persons) to have intrinsic moral importance. Included here are species, cultures, states, laws, universities, ecosystems, and some specific physical objects such as particular old redwood trees, the Taj Mahal, and Michelangelo's Pieta. Jeremy Bentham and many others would deny any intrinsic moral value to any of these, granting them at most derivative value consequent on their affecting or being valued by members of Groups $A$ and B. Other thinkers hold some or all of these to be genuine moral patients in their own right. There are a number of very basic, important, and difficult issues in moral theory involved in the countenancing of any moral patients in Group C. Fortunately, they need not be dealt with here, for our concerns are with Groups A and B and the relation between them.

Within Group A all moral patients are entitled to equal consideration. Each (human) person is taken to be of equal intrinsic value. Of course, if Jones is, and Smith is not, my parent, child, spouse, fellow soldier, fellow citizen, or one to whom I have made a promise, then my obligations to Jones may be stronger than my obligations to Smith. But in themselves, as persons, this view ranks Jones and Smith as moral peers.

Within Group B, in contrast, it is held that the moral status of creatures varies widely. Any Group B moral patient is, on this view, of vastly less significance than any Group A moral patient (person). But within Group B, one moral patient (a cat, say) may be much more important morally than another (a crab, perhaps). More serious justification is needed for harming or discomfiting the "higher" animals than for harming the "lower." One general principle, accepted at least verbally by almost everyone who has considered it, is that pain should not be inflicted needlessly on any sentient being. A second principle is that the higher 
(more intelligent, more aware) the being, the more urgent must be the need in order to justify the infliction of harm or pain. 5

To this more or less "official" view most of us subscribe. But our actions belie our words. We tolerate abominations such as bull fighting, fox hunting, leghold trapping, and fur ranching, in all of which "higher" animals are tortured for entertainment or status-display. For the production of expensive pate de fois gras and inexpensive chicken eggs we permit torture and incredible confinement. We are, further, inconsistent. Some of us protest with shock and dismay the sale of horses for meat but do not hesitate to eat a hamburger. Some of us bemoan the sale of pound animals for research and buy cosmetics needlessly tested in the eyes of rabbits. The use of very intelligent animals such as rats and primates for trivial and repetitive research is protested only by a very few.

Thus, even within the rational reconstruction of current moral sense that I have just sketched out there is a great deal of room for improvement in human treatment of nonhumans. But in fact the situation is much worse. For the assumption of a sharp break between groups $\mathrm{A}$ and $\mathrm{B}$ is spurious. It was clear to Aristotle and to many others before and since that humans are, after all, animals. Since the victory of Darwin, the fact that homo sapiens is one species among others has been part of the scientific outlook. It cannot plausibly be maintained, in the face of the science of the late 20th century, that there is a yawning gap between humans and the "merely sentient" rest of the animal kingdom. ${ }^{6}$

Nor is it possible to arrange animals on a single scala natura with humans clearly and safely at the top. Animals, humans included, have many sorts of characteristics and capabilities. To map these would require $n$ distinct continua or an $n$-dimensional continuum, with $n$ some number over 20 . It will not do simply to consider perception, for that resolves itself into the traditional five senses, plus echolocation, temperature sense, and several others, and then each category splits into three factors: range, sensitivity, and discrimination. What about locomotion? In what media? Speed or endurance? It seems clearly wrong to try to reduce intelligence to one measure, for we well know that we have not yet satisfactorily sorted out the varieties of human abilities covered by the term, and we have little reason to believe that the human varieties are the only ones there are. Similar remarks can be made about social behavior, communicative ability, manipulative skill, and tolerance of environmental change. There are other continua yet, such as longevity and fecundity. But we need not, fortunately, even attempt to discover how many such characteristics there are, for it is clear that not all differences between animals are morally significant. Consider the mouse and the bat.

The mouse and the bat are in many ways alike and in many ways different. If we plot their characteristics on our various dimensions or continua, we will find that on some they occupy nearly or exactly the same spot, and on some they are far apart. Bats echolocate, but mice (like us) score a zero on that. Bats fly, mice don't. Despite the fact that bats and mice are very different in these ways, they have (at least approximately) the same moral status. The different sensory and locomotor abilities of bats and mice are very important in making them the sorts of animals they are, making bats bats and mice mice. But in themselves these characteristics are of no moral importance. They may have some derivative moral significance. If, for instance, it is wrong to prevent a creature from moving in its natural way, then it is wrong to prevent bats from flying. But it is not wrong to prevent mice from flying. Still, the sensory and locomotor differences are not morally important per se.

In those characteristics that are morally significant, here sentience, intelligence, and self-awareness, bats and mice are, to the best of our knowledge, close together. So bats and mice have the same moral status and are due the same sort of consideration from humans. Of this pair of animals, the mouse is much more like us than the bat, but we are not morally obliged to care more about the mouse than the bat. One cannot just identify "morally significant characteristics" and "characteristics similar to those of humans."

Now suppose extraterrestrials to arrive from some distant star system. Suppose that they are intelligent, they are distinct individuals, and that they find some means of communicating with us. Beyond that, suppose that they are as different from us as you can imagine. They are predominantly gaseous, their chemistry is not based on carbon, their sensory apparatus is radically unlike ours and mostly operates on parts of the electromagnetic spectrum closed to us, and so on. But they are intelligent; they can communicate; they have a sense of self; and they are capable of suffering and enjoyment. They are, in short, persons. It makes a great deal of difference how we treat them. Their moral status, 
full personhood, is for many purposes far weightier than that of a mouse, despite the fact that the mouse is enormously more like us. As many philosophers have been insisting for years, "human" and "person" do not express the same concept. ${ }^{7}$ Given a choice between saving an irretrievably comatose human and one of these extraterrestrials, it would be wrong not to give preference to the extraterrestrial. The point is that morally relevant characteristics are a proper subset of all characteristics and are not those peculiar to humans.

What characteristics are morally significant, then? There is no clear consensus among moral philosophers on this question, but we can list some candidate characteristics. Sentience will appear on almost every list. By sentience is meant awareness of sensation and the ability to enjoy and to suffer. Those of us who think nothing of chopping up a live carrot but object to chopping up a live fish usually do so on the grounds that a fish is sentient and a carrot isn't. Other candidate characteristics include memory, a sense of self, the loose cluster of abilities called "intelligence," ability to communicate, concern for conspecifics, playfulness, and possession of an immortal soul.

Almost all of these candidate (for moral significance) characteristics are variable. ${ }^{8}$ An animal may have a more or less definite sense of self, be more or less sentient, may communicate more or less broadly and flexibly. Most of these, in other words, admit of degree. When one is ascribing some status, moral or other, on the basis of characteristics that can vary in degree more or less continuously, there is a strong temptation to a sort of fallacious reasoning I will call "magic lines or slippery slopes." Consider the height of adult male humans. There is considerable variation among populations, but in almost any context, a man $135 \mathrm{~cm}$ tall is short and a man $230 \mathrm{~cm}$ tall is tall. It seems plausible to say that a man .1mm taller than a short man is short, and a man .1mm shorter than a tall man is tall. A contradiction is easily obtained, for by adding and subtracting in units of .1mm it now can be shown that a man of any height one chooses is both tall and short. This sort of fallacy is the slippery slope. If one believes that slippery slopes can be prevented only by magic lines, one has to believe that there must be some precise height which marks the boundary between tall and short, or more plausibly, two precise heights dividing the range into tall, medium, and short. In this case, however, it is quite obvious that there are no such magic lines. There are no sharp demarcations between the short, the medium, and the tall. But some men are tall, some are short, and most are in between. There are no magic lines, but the slope is not slippery.

In moral matters we seem particularly liable to this sort of fallacious thinking. In the abortion controversy many find only extreme positions tenable, and others seek magic lines at conception or quickening or viability or birth.

It is instructive to consider a concept much like many of the concepts of moral status, that of maturity. (In fact maturity is in part a matter of moral status.) Almost all of the factors relevant to maturity vary in degree. For several purposes it is necessary to stipulate magic lines for maturity. For most purposes, in the United States, one is counted as legally mature at age 18 . But for marriage one may be counted as mature at age 16, and for the consumption of alcohol at 21 . If someone were to ask "But what is the age at which one is really mature?," he or she would betray deep ignorance of the concept or of the facts. At 18 Elmo may be mature sexually and politically, immature emotionally, intellectually, and physically. Some never attain emotional and intellectual maturity but must be counted as full-fledged adults. Even if we have all possible information about Sally, and agreement that she is mature, it will still probably not be possible to say precisely when she became so. There certainly is such a state as maturity, but there are no magic line criteria for it.

What is the application of all this to nonhuman animals? I want specifically to consider cetaceans, the whales and porpoises. What level of membership should they hold in the moral community? They obviously are sentient and, thus, moral patients of some sort. Even those few who favor continued whaling find it necessary to give at least lip service to the need for humane methods of killing. On the rational reconstruction of popular views offered above (and rejected as inadequate) everyone would place cetaceans at least in Group B. Some, still within the person/nonperson framework, would argue that (at least some) cetaceans should be placed in Group A, i.e., are persons. Champions of cetacean personhood point to a number of characteristics, including intelligence as shown in behavior and evidenced by large brains, complex social behavior including extensive mutual aid, playfulness both intra- and inter-specific, ability to communicate, interest in and solicitude for humans, inspiration of awe in humans, and unique places in ecosystems. 
I will set aside the last two items, because (a) that something inspires awe in humans does not even entail that it is sentient; consider the "starry heavens above and the moral law within" of Kant's famous line, ${ }^{9}$ and (b) as far as I can tell, everything that is part of any ecosystem has a unique place in that ecosystem.

Of the remaining characteristics, no one, and no pair, will suffice to establish the personhood of cetaceans (or of anything else). Many aninals, including insects, have complex social organizations with appropriate individual behavior. Some sort of communication has been observed in almost every vertebrate species, and notoriously in honeybees. Yet almost no one would suggest that the social and communicative honeybees are persons. Many animals play, and at least some (cats and dogs) play with members of other species. Many animals help one another. It is not uncommon, but it is futile, to attempt to find or construct a magic line in one or other of these characteristics. ${ }^{10}$

There remains intelligence. If information processing is central for intelligence, and intelligence criterial for personhood, it is but a short step to the question of rights for robots. If, on the other hand, one takes the adaptation of means to ends to constitute intelligence, then a vast number of species, including all the cetaceans, are well within the intelligent fold. But there are many varieties and aspects of intelligence, and even summing over them all, intelligence isn't everything. This is, of course, my point; no single characteristic is everything. There are no magic lines dividing fields of inoral status.

Cetaceans are entitled to special moral consideration not because of some single characteristic but because they possess very high degrees of a number of morally important characteristics. They are highly intelligent, highly social, and capable of sophisticated communication. It appears that at least some sorts of cetaceans may well have as much right to be considered persons as do humans. If, as I suggest, we abandon the sharp person/nonperson distinction, we can say that some cetaceans are at least quasi-persons.

Similarly, the conclusion that the great apes are at least quasi-persons is inescapable. They are highly intelligent, highly social, self-aware, communicative beings. Most of the rest of the primates probably deserve nearly the same status. Our mistreatment of our primate cousins is even less excusable than our mistreatment of cetaceans, since apes and monkeys are literally anthropomorphic. They are so obviously close to us-how can we use them as we do?

How should we treat quasi-persons? Clearly their enjoyment and suffering matter and must be taken into account. But that is surely not enough. We owe more than just consideration, we owe respect. We must respect their interests and their autonomy. The first thing we must do in regard to cetaceans and apes is to let them be, let them live their own lives as they choose. When their interests and ours come into conflict, as is sure to happen from time to time, interests must be weighed as impartially as possible. We owe quasi-persons, as we owe persons, consideration, respect, and justice.

There is no magic line between persons and the rest of the sentient world, and there are no magic lines within the sentient world. It is not just persons and quasi-persons but all conscious living things that are entitled, in many ways and to varying degrees, to consideration, respect, and justice. The levels of moral status are continuous, and can never reach zero while sentience remains.

Nothing I have said in this paper answers any specific questions about human treatment of nonhuman animals. I hope to have helped make clear that these are genuine moral questions and that moral questions are genuine questions.

\section{Notes}

1 This is a very extensively revised version of a paper, "Science, Ethics, and the Status of Cetaceans," written after a conference entitled "Cetacean Intelligence and Behavior and the Ethics of Killing Cetaceans," held in Washington, D.C., U.S.A., in 1980 under the auspices of the International Whaling Commission.

${ }^{2}$ For a useful survey and critique of modern ethics of virtue see Robert B. Louden, "Some Vices of Virtue Ethics," American Philosophical Quarterly, Vol. 21, No. 3 (July, 1984).

${ }^{3}$ Cora Du Bois, The People of Alor, (Minneapolis: University of Minnesota Press, 1944) (reprinted New York: Harper and Row, 1961), p. 106.

4 Translated title of paper delivered at the conference referred to in note 1 .

${ }^{5}$ Or death. But many would deny that it is wrong to kill a nonhuman animal, without denying that it is wrong to cause pain without need.

${ }^{6}$ Here and throughout this paper I am comparing adult animals of one species with adult animals of another. The questions of the moral status of nonhuman animals, of 
(human) abortion, and of (human) infanticide are closely related; all concern standing in the moral community. At six weeks a human seems clearly inferior to a beagle of the same age in every morally relevant characteristic. Why then do we assign higher status to the human infant? Are we justified in doing so? I am glad to be able, on grounds of length, to exclude such issues from this paper.

7 Of course the terms "human" and "person" are often used as synonymous, whether philosophers like it or not, but this causes considerable conceptual trouble. In Christian doctrine the three persons of the Trinity are all persons, but only one is human. On Star Trek the Klingons are persons, but not humans, and Mr. Spock is clearly a person although only half human. So, it is at least conceptually possible to be a person without being a human. That one may be a human without being a person is hotly denied in some quarters, affirmed in others. Fetuses and the comatose are central to this dispute. The less controversial cases of nonhuman persons suffice to show the need to separate these concepts.
${ }^{8}$ An exception is possession of an immortal soul Presumably this is not a matter of degree-either one has such a soul or one does not. But if it is held that all humans have such a soul and no nonhuman animals do, it would appear that it is much worse to kill a porpoise or a pigeon than to kill a human. The human's soul, on this view, continues to exist, but to deprive the animal of bodily existence is to deprive it of everything.

${ }^{9}$ Critique of Practical Reason, Conclusion, p. 161, Vol. $\mathrm{V}$ of the Prussian Academy edition.

${ }^{10}$ For example, those who would draw a magic line in communication, below which there is only signaling, and above which, in humans alone, lies true language, have been driven by ape language research to ever more desperate complications. Whatever can be found that at least some human linguistic behavior has and ape behavior lacks will be pronounced essential for 'real' language (until it is shown that the apes can do it).

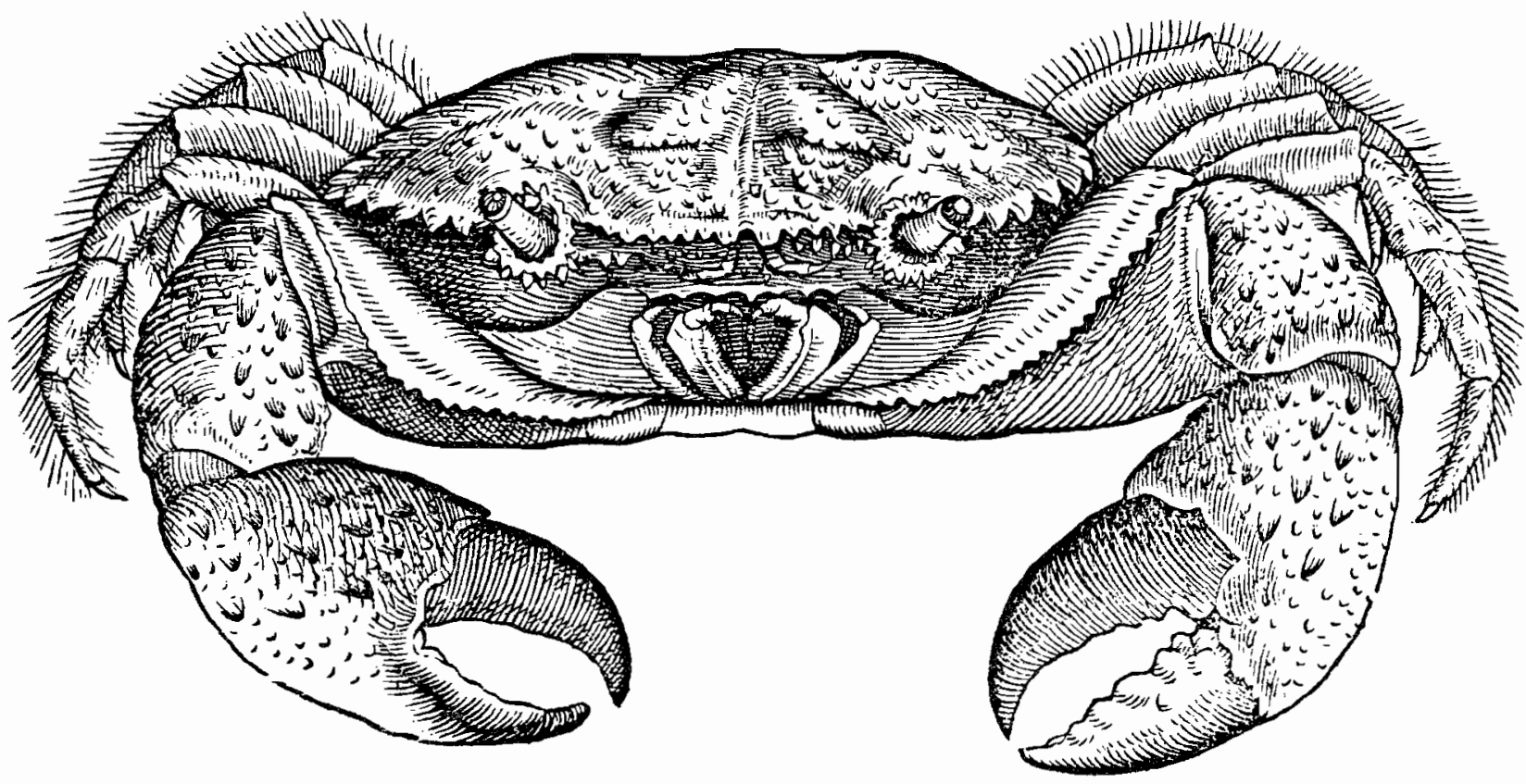

